\title{
DIALOGISMO NA REINVENÇÃO DO CURRÍCULO DA EDUCAÇÃO DE JOVENS E ADULTOS (EJA)
}

\author{
CAMPOS, Ana Maria de ${ }^{1}$ \\ FERREIRA, Dulcinéia de Fátima²
}

\begin{abstract}
RESUMO
Apresentamos este estudo como um convite para um diálogo sobre a reinvenção do currículo na Educação de Jovens e Adultos. O tema em apreço busca evidenciar sua não neutralidade, bem como a relação incontornável com campos de disputa manifestos na sociedade contemporânea. Afirma a existência de uma conexão entre currículo, poder, subjetividade e a constituição da identidade. Em face desta compreensão convida os sujeitos que atuam nesse campo a um trabalho de reinvenção das práticas relacionadas à produção do currículo na EJA, tendo em vista a necessidade premente de superação do modelo tradicional. Indicadores sociais, sobretudo os relativos à educação da população das camadas subalternas da sociedade, evidenciam a indispensável tarefa de rever práticas arraigadas em favor da criação de um currículo que esteja a serviço da vida, da emancipação social, da equidade no trato com os diferentes grupos geracionais demandantes da Educação de Jovens e Adultos em nosso país.
\end{abstract}

PALAVRAS-CHAVE: Educação de Jovens e Adultos; Currículo; Emancipação social.

\footnotetext{
${ }^{1}$ Licenciada em História. Mestre em Educação. Doutora em Educação na área de Ensino e Práticas Culturais pela Faculdade de Educação da UNICAMP. Pesquisadora no Grupo de Estudos e Pesquisas em Educação Continuada GEPEC, da Faculdade de Educação da UNICAMP. Professora no Programa de Pós-Graduação em Educação do UNISAL, campus Liceu, Campinas, SP. E-mail: belobelo_22@ yahoo.com.br

${ }^{2}$ Pedagoga. Mestre e Doutora em Educação pela Faculdade de Educação da UNICAMP. Professora Adjunto na Universidade Federal de São Carlos - UFSCar - campus Sorocaba, SP. Líder do Grupo de Pesquisa Educação, Comunidade e Movimentos Sociais - GECOMS - UFSCar - Sorocaba. E-mail: dulceferreira@ufscar.br
} 


\title{
e-Curriculum
} EDUCATION (EJA)

\author{
CAMPOS, Ana Maria de ${ }^{3}$ \\ FERREIRA, Dulcinéia de Fátima ${ }^{4}$
}

\begin{abstract}
We present this study as an invitation to a dialogue on the reinvention of the curriculum in the Youth and Adult Education (in Portuguese EJA). The topic at hand seeks to demonstrate its non-neutrality, and the inescapable relationship with dispute fields, manifest in the contemporary society. It affirms the existence of a connection between curriculum, power, subjectivity and constitution of identity. Given this understanding invites individuals working in this field to a reinvention of work practices related to the production of the curriculum in adult education, in view of the urgent need to overcome the traditional model. Social indicators, especially those related to education of the population of the lower strata of society, demonstrate the essential task of reviewing practices rooted in favor of creating a curriculum that is at the service of life, social empowerment and fairness in dealing with a different plaintiffs generational groups in the Youth and Adult Education in our country.
\end{abstract}

KEYWORDS: Youth and Adult Education; Curriculum; Social emancipation.

\footnotetext{
${ }^{3}$ Graduate in History. Master's in education. PhD in Education in the area of Teaching and Cultural Practices by the School of Education of UNICAMP. Researcher in the Group of Studies and Research in Continuing Education - GEPEC, Faculty of Education of UNICAMP. Professor at the Graduate Program in Education at UNISAL, Campus Liceu, Campinas, SP.E-mail: belobelo_22@yahoo.com.br

${ }^{4}$ Pedagogue. Master and PhD in Education from the Faculty of Education of UNICAMP. Adjunct Professor at Federal University of São Carlos - UFSCar - Sorocaba campus, SP. Leader of the Research Group Education, Community and Social Movements - GECOMS - UFSCar - Sorocaba. E-mail: dulceferreira@ufscar.br
} 


\title{
1 INTRODUÇÃO: A RELAÇÃO ENTRE VIDA E EDUCAÇÃO
}

Quero falar de uma coisa,

adivinha onde ela anda?

deve estar dentro do peito, ou caminha pelo ar

pode estar aqui do lado

bem mais perto que pensamos

Milton Nascimento e Wagner Tiso

Ao apresentarmos o convite para o diálogo sobre a produção do currículo na Educação de Jovens e Adultos - EJA, carregamos conosco conceitos e teorias que sustentam a nossa ação pedagógica. Como nos ensinou Paulo Freire as pessoas encarnam uma teoria, mesmo que não reflitam continuamente sobre o tema:

\begin{abstract}
Será que a prática educativa pode se dar sem se constituir numa situação de conhecimento? Será que é possível que, de um lado, o educador e, do outro, os educandos podem se encontrar numa sala, ou debaixo de uma árvore, não importa, sem que esteja em jogo algo a se conhecer? Eu acho que não é possível. Eu acho, por isso, que a educação, não importando o grau em que ela se dá, é sempre uma certa teoria do conhecimento que se põe em prática (FREIRE, 1989, p. 95).
\end{abstract}

Assim, entendemos que os debates realizados em torno do currículo na EJA não são diferentes. Quando nos propomos a sentar em uma roda de educadoras e educadores para dialogarmos sobre nossas inquietações relativas ao currículo trazemos conosco as preocupações sobre: O que ensinar? Qual conteúdo deve ser valorizado? "Qual o conhecimento ou saber é considerado importante ou válido ou essencial para merecer ser considerado parte do currículo?" (SILVA, 2001, p.15). Como cantou o poeta, também queremos "falar de uma coisa, que deve estar dentro do peito, bem mais perto que pensamos". (NASCIMENTO; TISO, 1983).

Desejamos abordar neste trabalho a necessidade de situarmos as argumentações sobre o que? e como? ensinar para além dos domínios da escolarização, pois tais escolhas estão relacionadas à forma como é concebida a sociedade, a apropriação e circulação do conhecimento, enfim, à formação humana. São, portanto, componentes de um processo sociocultural que se vive no cotidiano das instituições escolares.

Os debates acadêmicos demonstram que as interrogações relativas ao currículo ultrapassam aspectos meramente técnicos, como pode ser facilmente observado através da leitura dos trabalhos publicados nas reuniões da Associação Nacional de Pós-Graduação e 


\section{$e$-Curriculum}

Pesquisa em Educação - ANPEd ou em livros que abordam a temática curricular (SILVA, 2001; COSTA, 2005; GRANVILLE, 2011, para citar apenas alguns autores).

Quando nos perguntamos sobre o quê ensinar? estamos fazendo escolhas, selecionando o que deve ou não fazer parte de um processo educativo, pois "teorizar sobre currículo e pedagogia implica teorizar sobre a prática escolar" (MOREIRA, 2005, p.30). Explicitamos opções políticas, pois o currículo praticado está encharcado de nossas visões de mundo, de nosso modo de atuação na sociedade e de nossas projeções de futuro. Tudo isso se manifesta na maneira em como vivenciamos a relação pedagógica, ou seja, aquela que se dá no encontro entre educadoras, educadores, educandas e educandos, a qual interfere decisivamente na constituição dos sujeitos implicados no ato educativo. Segundo Antônio Flávio Moreira (2005, p.28) "qualquer projeto educativo se materializa em atividades localizadas, vivenciadas por sujeitos específicos, espacial e temporalmente situados", visto que o encontro pedagógico é sempre "local, parcial e múltiplo".

Pelas razões apresentadas, podemos afirmar que o debate não acontece em território neutro. Ao selecionarmos o que ensinar? damos a ver a relação estabelecida entre pessoas, apontando para um tipo de formação humana que interfere na organização da sociedade. A pergunta o que ensinar? está diretamente relacionada com questões de poder, pois ela vem invariavelmente acompanhada de outra pergunta nem sempre pronunciada explicitamente: "o que elas ou eles devem ser, ou melhor, o que eles ou elas devem se tornar?" (SILVA, 2001, p.15).

A seleção sobre o que ensinar? sugere existir um horizonte para além do campo estritamente pedagógico. É pertinente afirmar que tratamos também da constituição de sujeitos, de subjetividades, de identidades, de modos de ser e estar no mundo. Segundo nosso entendimento, este é um enfoque crucial no debate sobre currículo, pois geralmente,

[...] quando pensamos em currículo, pensamos apenas em conhecimento, esquecendonos de que o conhecimento que constitui o currículo está inextricavelmente, centralmente, vitalmente, envolvido naquilo que somos, naquilo que nos tornamos: na nossa identidade, na nossa subjetividade (SILVA, 2001, p.15).

Os aportes teóricos da área em questão nos ajudam a reafirmar a necessidade de compreendermos que as escolhas feitas na organização de um currículo não são neutras ou desinteressadas, ao contrário, estão relacionadas, às vezes, de forma invisível, às disputas de forças que ocorrem na sociedade. As opções que fazemos estão expostas nos modos de conceber 
o currículo, carregando, dessa maneira, a nossa concepção de qual ser humano pretendemos formar e, por extensão, de qual sociedade trabalhamos para construir. Em 1992, por exemplo, o pesquisador Tomaz Tadeu da Silva publicou importante estudo no qual apresentava ponderações sobre as contribuições que o currículo pode oferecer para a construção de uma sociedade mais justa e democrática (SILVA, 1992).

Na teoria tradicional o currículo é compreendido como um produto, elaborado de modo prescritivo, estando circunscrito a um suposto campo técnico-pedagógico. Suas características estão vinculadas às listas de conteúdo, ao ensino, aprendizagem, avaliação, metodologias, planejamento, eficiência, objetivos, os quais são apresentados como supostamente neutros. Segundo Antônio Flávio Moreira (2005, p. 20) a concepção tradicional do currículo começou a ser criticada nos Estados Unidos por volta do início do século XX, porém foi sendo aprofundada a partir da década de 1970, explicitando,

a rejeição do caráter prescritivo prevalente; da certeza da não-neutralidade das decisões curriculares; da visão de que escola e currículo não podem ser analisados sem referência aos contextos mais amplos que os envolvem; bem como da crença na importância da escola no processo de construção de uma sociedade mais democrática e mais justa. É no interior desse movimento que se encontram as raízes da teoria crítica de currículo americana.

No Brasil as críticas ao currículo tradicional remontam ao final da década de 1970, no mesmo período em que se dava a abertura política, ainda na vigência da ditadura militar. "É nesse momento que explode, em todo país, uma literatura pedagógica de cunho mais progressista" (MOREIRA, 2005, p. 15).

A despeito de todo movimento de crítica ao currículo tradicional ainda observamos nos contextos escolares práticas autoritárias e alheias ao universo cultural dos educandos e educandas. Na tese de doutorado "Histórias contidas e nem sempre contadas na formação de jovens e adultos" (CAMPOS, 2014), são narradas dramáticas experiências de sujeitos que tiveram seus percursos escolares interrompidos, todavia criaram mecanismos para retornarem e permanecerem na escola, apesar de todas as interdições sofridas ao longo da vida. Tais interdições se manifestaram sobretudo na precoce convocação para o trabalho, como também no modo como está organizada a grande maioria das instituições escolares, distantes do universo cultural dos estudantes. 
O modo tradicional de pensar e praticar o currículo, sobretudo na EJA, traz de forma implícita uma concepção de ser humano racional e de uma sociedade injusta e desigual, onde de um lado estão postados aqueles que detêm o saber e, por isso, podem e devem prescrever, e de outro, pessoas que estão vazias de conhecimentos, motivo pelo qual são alvo da transmissão de conteúdos previamente selecionados pelos que têm a posse dos conhecimentos.

Podemos afirmar que o currículo, pensado somente como uma lista de conteúdo a ser trabalhado, não possibilita a reinvenção do modo como estamos vivendo, visto estar a serviço da repetição do presente, por conseguinte, da repetição da forma como a vida vem se realizando nesta sociedade excludente. Este modelo, como demonstram os estudos, acaba por promover a manutenção do status quo.

Na medida em que o poder de seleção sobre o quê ensinar? está nas mãos de uma equipe de técnicos, que além de determinar o quê? define também o como ensinar, o currículo, na visão tradicional deixa de lado uma questão essencial que está relacionada ao por que? ensinar estes e não outros conteúdos. Algumas perguntas fundamentais a serem feitas, neste caso são: O que tais conteúdos implicam na vida dos educandos e educandas? Qual a contribuição efetiva desses estudos no seu cotidiano? Os conteúdos abordados colaboram para a promoção da vida? Atendem às demandas dos jovens e adultos e valorizam os seus saberes e experiências? Se estas questões não forem tangenciadas o currículo praticado continuará sendo um instrumento de poder a serviço da dominação e da manutenção da segregação social.

Defendemos uma concepção e vivência de currículo na qual a pergunta sobre o que ensinar? esteja intimamente associada à questão por que? ensinar. Reafirmamos que nossas opções não ocorrem descoladas da visão de ser humano com o qual trabalhamos, bem como de qual projeto de sociedade contribuímos para construir. Afirmamos a ideia de currículo impregnado de intencionalidade, por isso mesmo, de não neutralidade. Segundo Tomaz Tadeu da Silva (2001, p. 150):

Currículo é lugar, espaço, território. O currículo é relação de poder. O currículo é trajetória, viagem, percurso. O currículo é autobiografia, nossa vida, curriculum vitae: no currículo se forja a nossa identidade. O currículo é texto, discurso, documento. $\mathrm{O}$ currículo é documento de identidade. 


\section{DIÁLOGO: NECESSIDADE EXISTENCIAL}

há que se cuidar da vida

há que se cuidar do mundo tomar conta da amizade alegria e muito sonho espalhados no caminho

Milton Nascimento e Wagner Tiso

Cantamos com o poeta que "há que se cuidar da vida" e "há que se cuidar do broto pra que a vida nos dê flor e fruto" (NASCIMENTO; TISO,1983). Nosso trabalho está voltado ao cuidado com o broto, ou seja, com as vidas com as quais nos relacionamos no encontro educativo.

Na nossa seara estamos empenhadas na construção de novas possibilidades para a vida se manifestar. Aprendemos com Paulo Freire (1981, p. 93) que na relação pedagógica o diálogo é fundamental: "o diálogo é uma exigência existencial” pois "somente na comunicação tem sentido a vida humana" (1981, p.73). Compreendemos, portanto que,

O diálogo é este encontro dos homens, mediatizados pelo mundo, para pronunciá-lo, não se esgotando, portanto, na relação eu-tu [...] Se é dizendo a palavra com que, "pronunciando" o mundo os homens o transformam, o diálogo se impõe como caminho pelo qual os homens ganham significação enquanto homens. Por isto, o diálogo é uma exigência existencial (FREIRE, 1981, p. 93).

Assim, defendemos o currículo como parte de um processo de emancipação e não como regulação, como critica Boaventura de Sousa Santos (1996). Ao encarnarmos esta postura assumimos que o modo como compreendemos e vivenciamos o currículo faz diferença na nossa atuação, pois a teoria de currículo incorporada, impregnada em nosso ser, interfere diretamente no modo como estamos sendo no mundo (FREIRE, 2000, p. 79). Romualdo Dias (2004, p. 4) destaca que:

Neste nosso modo de entender o processo educativo enquanto um exercício de poder a serviço da expansão da vida nós queremos unir o poder da leitura e o poder da escrita com um outro trabalho. Queremos que cada educando e cada educador possam viver um processo de re-significar modos de estar na vida. Pois, assim, estaremos ampliando nosso poder no campo da construção do sentido de vida.

Entendemos a EJA como um espaço/tempo de ampliação das possibilidades da vida se manifestar. Por isso insistimos que o debate sobre currículo neste segmento da educação é 


\section{e-Curriculum}

urgente, pois uma teoria de currículo interiorizada repercute no modo como educadoras e educadores atuam em aula, já que nos movemos no mundo a partir das "marcas" presentes em nossos corpos (ROLNIK, 1993).

A pertinência e atualidade do debate pode ser avaliada ao nos reportarmos aos recentes dados publicados pelo Instituto Brasileiro de Geografia e Estatística - IBGE (2013) revelando que existe no Brasil 56 milhões de pessoas que não completaram o Ensino Fundamental. Em um universo de 200 milhões de brasileiros, uma em cada três pessoas, acima de 15 anos, ainda não teve oportunidade de concluir o nível básico da escolarização (SOARES; SILVA; SOARES, 2015, p.01).

Também podemos acrescentar os dados publicados em 29 de janeiro de 2014 pela Organização das Nações Unidas para a Educação, a Ciência e a Cultura - UNESCO, no $11^{\circ}$ Relatório de Monitoramento Global de Educação para Todos, no qual afirma que a taxa de analfabetismo no Brasil não caiu significativamente nos últimos anos.

Na mesma data da divulgação do relatório da UNESCO, a revista online Carta Capital publicou uma reportagem sobre esse documento, mencionando o fato de que os indicadores foram elaborados a partir da Pesquisa Nacional por Amostras de Domicílios - PNAD, de 2011, também produzida pelo IBGE. Pelos indicadores da PNAD houve ligeira queda do analfabetismo no país, recuando para uma taxa de $8,6 \%$, em relação ao que foi apurado no censo de 2010. Esse percentual corresponde a 12,9 milhões de vidas. Ou, abordando de outro prisma, milhões de brasileiros continuam sem acesso aos direitos universais proclamados em nossa Constituição. Milhões de vidas são invisibilizadas pelos números e suas histórias ficam soterradas em pilhas de planilhas (CAMPOS, 2014).

Observar os índices não é suficiente para conhecer os dramas humanos neles escondidos, porém, o ato de invocá-los já nos compromete com esta situação de negação de direitos fundamentais. "É já uma tomada de posição em relação ao outro escondido por entre os interstícios das planilhas" (CAMPOS, 2014, p. 154). De acordo com Álvaro Vieira Pinto (1991, p. 97) “o que os índices, curvas e gráficos revelam, são essencialmente fatos sociais, que, como tais, só podem ser entendidos em profundidade quando são relacionados com seu significado humano". 
Entendemos que os indicadores sociais apresentados nos convidam a interrogar sobre as práticas levadas a efeito nas instituições escolares, em especial na construção do currículo da EJA.

Para pensarmos e vivenciarmos um currículo como perspectiva dialógica, implicado com a emancipação "cognitiva, interacional e societal” (SANTOS, 1996), precisamos desconstruir modelos e ideias socialmente instituídos e impregnados em nossos corpos e, portanto, em nossas práticas. Necessitamos urgentemente reinventar o nosso modo de ser e estar na EJA, nos deslocando do lugar acostumado da teoria tradicional de currículo para um outro território que o concebe como processo vivido em uma relação dialógica, de constituição de sujeitos. Nesta perspectiva as relações humanas são estabelecidas como "encontro amoroso dos homens que, mediatizados pelo mundo, o pronunciam, isto é, o transformam" (FREIRE, 1992, p. 43). Aqui, então, se evidencia a noção de currículo como manifestação de saber, poder e constituição do sujeito a partir da relação com o outro, ou seja, como processo histórico e cultural.

Queremos nos reportar à vida das pessoas que saem todas as noites de suas casas e se permitem experimentar a riqueza do encontro humano. Pessoas que movidas por desejos, necessidades inadiáveis ou desassossegos, rompem com a lógica instituída nesta sociedade excludente e voltam a estudar. Voltam a acreditar, mesmo sem ter consciência disso, no seu potencial criador latejante dentro de si. Queremos falar, como o poeta, desta inquietação que coloca muitos educandos, educandas, educadores e educadoras em movimento, em busca de algo que faça sentido para suas vidas.

O tempo que vivemos hoje nos provoca indagações. A partir de Santos (1996), podemos dizer que vivemos um tempo de transições paradigmáticas. Nunca foi tão contrastante a distância entre os saberes produzidos pela humanidade e a precariedade da vida. Como educadoras, não podemos negar que somos afetadas pelo percurso que a humanidade caminhou e pelo contexto atual.

Neste cenário de incertezas e de trivialização dos conflitos e dos sofrimentos humanos se insere o debate sobre um currículo na EJA a serviço da vida. Segundo Luis Carlos Restrepo (2001, p. 19 e 20), 


\section{$e$-Curriculum}

Nós cidadãos ocidentais sofremos uma terrível deformação, um pavoroso empobrecimento histórico que nos levou a um nível jamais conhecido de analfabetismo afetivo [...] que dificulta compreender as raízes de nosso sofrimento. Analfabetismo que nos impede de encontrar chaves para melhorar nossa vida cotidiana.

Diante dessa conturbada situação, não é razoável continuarmos a atuar no âmbito da Educação de Jovens e Adultos sem apresentar nossos incômodos com o modo como o currículo é pensado e vivenciado em muitos lugares. O compromisso ético e político com a educação nos provoca a olhar para os indicadores sociais como contundente demonstração de que se faz necessário a viabilização de mudanças. Pensamos que podemos agir a partir da problematização do currículo inspiradas nas concepções da Educação Popular (FREIRE e NOGUEIRA, 2005; BRANDÃO, 1984; GARCIA, 1984) ao lado de uma atuação em parceria com os movimentos sociais, a fim de pressionar governantes no sentido de assumirem a EJA como política de estado, com pactos evidentes e duradouros no que tange ao seu financiamento e à formação inicial e continuada dos educadores e educadoras.

Percebemos que há um desassossego na sociedade. Educadoras, educadores, educandos e educandas, cada qual ao seu modo e estilo estão em busca de alternativas. Os Fóruns de EJA em todo o território nacional são mostras do desejo de mudança e de novas propostas para a construção do currículo, da organização das redes de ensino, bem como do financiamento, das relações entre instituições e órgãos governamentais (como pode ser observado no endereço eletrônico do Fórum EJA Brasil: <http://forumeja.org.br/brasil〉).

Educandos e educandas que não tiveram garantido o seu direito de estudar na infância, via de regra, buscam na escolarização os conteúdos valorizados pela sociedade capitalista, no nosso caso, apoiados em uma cultura eurocêntrica, colonizadora, racista e patriarcal. Conforme Barreto (2005), podemos afirmar que há na vida desses estudantes a explicitação de uma contradição entre o desejo de emancipação e, ao mesmo tempo, da valorização dos conteúdos hegemonicamente impostos pelos meios disseminadores da ideologia capitalista. Nesse cenário contraditório a construção de um currículo a partir do diálogo entre os sujeitos pode promover a partilha de saberes outros, indispensáveis para a compreensão de como são produzidas e mantidas as hierarquias sociais mantenedoras e alimentadoras do apartheid social:

a investigação inicial do universo vivido pelos sujeitos e seus percursos existenciais favorecem uma aproximação, como também um olhar mais atento e crítico sobre o seu contexto social. As vivências dos membros do grupo utilizadas como plataforma de lançamento para a compreensão e desvelamento da realidade da sociedade dividida 
em classes, aproxima sem hierarquizar, educadores e educandos. As pessoas vão criando juntas a oportunidade de apreender a realidade, levantando o véu que encobre a razão do mundo capitalista ser organizado sob o fundamento da exploração do trabalho humano. É possível a explicitação da condição social do apartheid de direitos experimentado pelas vidas que carregam em si mesmas as marcas do pertencimento de classe (CAMPOS; PACHANE, 2012, p. 224).

Dialogar sobre as histórias de vida dos sujeitos da EJA, assim como sobre suas demandas existenciais, faz toda a diferença na produção do currículo a serviço da emancipação humana. As experiências e teorizações elaboradas desde o campo da Educação Popular mostram que "a centralidade do processo educativo está na produção do conhecimento e não na pura e simples reprodução e transmissão de conteúdos, ainda muito frequente em nossos dias" (CAMPOS; PACHANE, 2012, p. 223), num tipo de reprodução interminável do que Paulo Freire (1981) chamou de "educação bancária".

A busca do educando e da educanda da EJA é por um conhecimento que favoreça o seu trânsito na sociedade letrada, com domínio e propriedade. Esses sujeitos desejam resgatar a humanidade roubada ampliando seus horizontes, com uma participação social compatível com a dignidade de todo ser humano. Esses sujeitos querem ser reconhecidos e valorizados. Todavia, como afirmou Paulo Freire (2000, p. 84),

É importante salientar que o novo momento na compreensão da vida social não é exclusivo de uma pessoa. A experiência que possibilita o discurso novo é social. Uma pessoa ou outra, porém, se antecipa na explicitação da nova percepção da mesma realidade. Uma das tarefas fundamentais do educador progressista é, sensível à leitura e à releitura do grupo, provocá-lo bem como estimular a generalização da nova forma de compreensão do contexto.

O processo dialógico instaurado nas relações entre educadores, educadoras, educandos e educandas promove a partilha de saberes e possibilita a construção do currículo a partir do universo cultural dos sujeitos:

Primeiro os pés: não é o discurso que ajuíza a prática, mas a prática que ajuíza o discurso. Primeiro o fazer, que abre o campo do possível. Possível e fazer que estão atrelados ao poder, ao poder de cercear e ao poder de criar. Nós, educadores, que usamos a palavra como instrumento de trabalho, somos submetidos ao desafio de dividi-la, de forma criativa, com o outro. Para que o outro, afiando esse instrumento, possa potencializá-lo na reconstrução de si mesmo (GARCIA, 2001, p. 83).

Ao buscar a EJA o educando, a educanda, rompe com o modelo de exclusão instituído, desafia-se e desafia a sociedade. Coloca-se em movimento, desloca-se para um território até então negado. Desloca-se em busca do saber, do poder saber. Tal movimento não acontece em 


\section{$e$-Curriculum}

território neutro. Educandas e educandos vêm marcados por suas histórias, pelos embates com forças políticas que disputam a hegemonia na sociedade.

Como afirmamos anteriormente, jovens e adultos que buscam a escolarização, geralmente, portam a ideia hegemônica de escola incutida em suas vivências (BARRETO, 2005). Justamente uma ideia que impossibilita sua emancipação, pois corresponde ao modelo responsável pela sua expulsão do convívio escolar. Modelo que operou ideologicamente para que em seu corpo fosse forjada a imagem de incompetência, de ignorância, de incapacidade para aprender. Esses educandos e educandas vivem um conflito de complexa superação, pois buscam a reinvenção do modo de existência, porém se agarram a modelos tradicionais de escola.

Esse modelo de educação escolar corresponde ao que Paulo Freire (1981) questionou e chamou de "educação bancária", abordado em páginas anteriores deste artigo. Nele educadores e educadoras são os detentores do saber e por isso são os que ensinam. Educandos e educandas, por oposição, são os que nada sabem e precisam aprender. Muitos jovens e adultos, ao voltarem a estudar, não acreditam mais em seu potencial. Chegam a afirmar que "a cabeça é dura" ou que "a memória é fraca" (PEREIRA, 1999). O que, na verdade, não sabem é que esse sentimento de impotência foi sendo introjetado no seu inconsciente de forma sorrateira e quase imperceptível, durante toda a vida. Muitos também ainda não reconhecem o fato de que possuem um grande potencial dentro de si.

No geral esses jovens e adultos encontram dificuldades para reconhecer que uma pessoa que consegue sobreviver no mundo letrado, sem saber ler e escrever, ou tendo pouco domínio da leitura e da escrita, demonstra uma grande capacidade criadora! Capacidade tal que possibilita elaborar mecanismos para driblar as artimanhas de um sistema opressor e excludente. É uma pessoa dotada de um gingado próprio, um estilo e manha com os quais vai inventando as peripécias para sobreviver e enfrentar as intempéries da vida. Como ensinou Michel de Certeau: "Essas táticas manifestam igualmente a que ponto a inteligência é indissociável dos combates e dos prazeres cotidianos que articula". (2008, p. 47).

Em nossos estudos pudemos perceber que,

Falando da vida, o educando vai fazendo história, vai resgatando sua própria história de vida pessoal e apropriando-se da história da humanidade, tomando consciência de suas conquistas, seu crescimento, que não está no começo e que não possui fim, mas que é um processo que se desenvolverá por toda vida. Para isto é necessário que falem 
Quando jovens e adultos buscam a instituição escolar trazem consigo seus saberes de experiência feitos (FREIRE, 2000a, p. 101; FREIRE, 2000b, p. 83; LARROSA, 2004, p. 129), sua arte, seu estilo de viver, seu ritmo. Essas pessoas não chegam vazias na Educação de Jovens e Adultos. A pele vem marcada por uma história rica de acontecimentos, cheia de lutas, conquistas e derrotas, alegrias e dores. De acordo com Rolnik (1993), tais marcas estão prontas para serem reatualizadas ou potencializadas.

Entendemos que a capacidade de resistir, de não se entregar às dificuldades, de reinventar a vida, contribui para que jovens e adultos rompam com o modelo de exclusão vigente e ultrapassem novamente os muros das escolas, desta vez, porém, fazendo o caminho inverso. Eles se deslocam de fora para dentro e começam a ocupar espaços e territórios negados ou proibidos.

\title{
3 ARTÍFICES NA PARTILHA DE SONHOS
}

\author{
o seu olhar lá fora \\ o seu olhar no céu \\ o seu olhar demora \\ o seu olhar no meu [...] \\ o seu olhar seu olhar melhora \\ melhora o meu
}

Arnaldo Antunes e Paulo Tatit

Muitas educadoras e educadores da EJA, assim como educandos e educandas, são pessoas impregnadas de histórias de superação e de inconformismo com a realidade obtusa. Carregam consigo sinais indeléveis de histórias vividas, forjam um estilo peculiar de enfrentamento da realidade de precariedade, além de apresentarem muitas inquietações. Seus olhares são interpelativos convidando ao diálogo. Durante nossos anos de trabalho na EJA ou em grupos alternativos de Educação Popular, atuando na formação de educadores e educadoras, pudemos observar que um grande número de pessoas que participa de projetos de Educação Popular ou que optam por atuar na Educação de Jovens e Adultos, é portadora de um diferencial, 


\section{$e$-Curriculum}

Programa de Pós-Graduação em Educação: Currículo

uma certa inquietação e desassossego com a forma como a educação vem ocorrendo, com o que? se ensina e por que?.

Notamos em nossas vivências que em muitas situações o educador, a educadora da EJA escolheu atuar nesse segmento educacional. São pessoas que desejam participar do trabalho desenvolvido junto aos jovens e adultos pouco escolarizados. É certo que essa não é a totalidade dos casos, porém não pode ser ignorada a fração que faz essa opção. O desejo de estar onde está, bem como a vontade de intervir nesse contexto educacional faz toda a diferença! O modo de ser e estar desses educadores e educadoras nos espaços/tempos da EJA tem estilo próprio. "Há um jeito artístico de aprender e de ensinar. Há um jeito artístico de construir conhecimento e utilizar saberes" (DIAS, 2004, p.8).

Para esses sujeitos a educação é campo de possibilidades de novas experimentações, pois a aula é acontecimento (GERALDI, 2010), espaço/tempo de criação, onde diversas culturas, diversos saberes se encontram, se interpenetram, se modificam. Sujeitos do processo educativo, educandos e educadores, reconhecem que nesse território de diversidade o conflito, a incerteza, os encontros e desencontros fazem parte da invenção da vida.

Diante dessas observações notamos que tais pessoas feridas pelas vicissitudes cotidianas, vivendo em situações de precariedade, necessitam e buscam o reconhecimento. Buscam confirmação e apoio para mergulharem com coragem no campo da produção e apropriação de conhecimentos.

A relação humana, impregnada pela intensidade e fragilidade, entre pessoas jovens e adultas, educandos, educandas, educadores e educadoras remete ao debate sobre currículo, sobre o que estamos ensinando na EJA. Quais sonhos alimentamos em relação à vida dessas pessoas? Qual o horizonte de futuro intentamos criar durante o tempo/espaço vivido na EJA? Que seres humanos estamos formando? Por que optamos por trabalhar com esses e não outros conhecimentos? Quais sentidos imprimimos ao que temos estudado? Qual a relação entre estudo, diálogo e a vida dos sujeitos do processo de ensino?

Diálogo, aqui, vem no sentido de compartilhar a vida, implica em "falar com" e não "falar para" ou "sobre". "Falar com" implica em alguém dizer a sua palavra, compartilhar a sua experiência, dúvida, desejo com o outro, e esse em diálogo se põe na posição da escuta, da acolhida, da colaboração (PEREIRA, 2006, p. 92).

Encharcadas das inquietações apresentadas e incomodadas com a distância entre a vida e o modo como a relação com o conhecimento vem se mantendo e se reproduzindo na Educação 
de Jovens e Adultos, temos procurado os indícios em nossas experiências, nas teorias e nas pesquisas no campo do currículo, que nos auxiliem na reinvenção do modo como temos vivido e praticado o currículo na EJA.

Não temos intenção prescritiva, ao contrário, trazemos interrogações e sinais de que é possível reinventar as práticas a partir do diálogo, da criação conjunta de um currículo vivo, que faça sentido para as pessoas que o estão produzindo na experiência cotidiana. São pistas possivelmente potentes para nos ajudar a redesenhar os nossos mapas societais, cognitivos e interacionais (SANTOS, 1996).

Transformações perceptíveis no cotidiano são elaboradas em ambientes onde há diálogo, por meio do qual também engendramos as possibilidades de construção de conhecimento. Neste tipo de atitude há sempre uma ação entre sujeitos que se ensinam e que mutuamente aprendem, pois, “aprender é criar com o outro o seu próprio saber”. (BRANDÃO, 2003, p. 254).

Como nos ensinou Paulo Freire (1984, p.84),

Na verdade, se dizer a palavra é transformar o mundo, se dizer a palavra não é privilégio de alguns homens, mas um direito dos homens, ninguém pode dizer sozinho a palavra. Dizê-la sozinho significa dizê-la para os outros, uma forma de dizer sem eles e, quase sempre, contra eles. Dizer a palavra significa, por isso mesmo, um encontro de homens. Este encontro que não pode realizar- se no ar, mas tão-somente no mundo que deve ser transformado, é o diálogo em que a realidade concreta aparece como mediadora dos homens que dialogam ${ }^{\mathrm{i}}$ (grifos do autor).

A partilha da palavra e a escuta da contra palavra na construção do currículo vivo é das experiências mais provocativas e transformadoras na vida das pessoas, como temos experimentado em nossas próprias vidas, tanto atuando na formação de educadores e educadoras, como na pesquisa educacional realizada na área.

\section{CONSIDERAÇÕES FINAIS: ANÚNCIO - FINALIZANDO SEM ENCERRAR...}

Quero a utopia, quero tudo e mais quero a felicidade dos olhos de um pai

quero a alegria, muita gente feliz quero que a justiça reine em meu país

Milton Nascimento e Fernando Brant 


\section{e-Curriculum}

Para nos despedirmos temporariamente do diálogo que vimos estabelecendo até aqui gostaríamos de compartilhar algumas reflexões que temos desenvolvido ao longo de nossas vidas de educadoras.

Em uma experiência de Educação Popular vivida por nós na Secretaria Municipal de Educação de Campinas, SP, na implementação e coordenação na cidade do Projeto LETRAVIVA, versão local do Programa Brasil Alfabetizado, do Ministério da Educação MEC, tivemos oportunidade de viver intensamente a ressignificação do currículo na Educação de Jovens e Adultos. Em um texto apresentando esse trabalho, nosso companheiro de jornada, Romualdo Dias (2004, p.9-10), fez referência a três dimensões da vida que estão presentes na educação e, portanto, relacionadas ao debate sobre o currículo a serviço da vida na EJA. São elas: a sobrevivência, a convivência e a revivência.

Em relação às condições materiais de existência dos sujeitos afirma o autor:

Há uma dimensão da vida que se refere às condições materiais para continuar vivo, que é a dimensão da sobrevivência. Aqui, o processo educativo pode propiciar um exercício de ampliação das condições de vida de cada educando. Pode também estimular os educandos na criação de novas fontes de trabalho, como um laboratório permanente de ensaio. A ampliação das condições materiais de vida depende do desenvolvimento de habilidades. Estas habilidades podem ser ensinadas. Por exemplo, a habilidade de construir uma casa pode ser ensinada por um pedreiro. A habilidade de cozinhar pode ser ensinada por quem sabe cozinhar. A habilidade de costurar pode ser ensinada (DIAS, 2004, p. 9).

A dimensão da convivência implica no reconhecimento de nossas fragilidades e potencialidades:

Nós, enquanto seres humanos, diferentes dos outros animais, nascemos com muita fragilidade e dependemos de alguém para sobreviver. Precisamos dos vínculos. Nesta dimensão da convivência nós tecemos os vínculos, criamos os laços, vamos ao encontro do outro para nos completar. Aqui, o processo educativo pode propiciar um exercício de ampliação das condições de vida de cada educando. Pode também estimular os educandos na criação de novos vínculos. Podemos desenvolver a solidariedade. A ampliação dos nossos vínculos depende da formação de atitudes. A nossa atitude diante da vida traça o nosso estilo de procura e de abertura para o encontro com o outro. Esta atitude é formada a partir do momento em que cada um elabora o fato da precariedade de sua vida. E depois, vai ao encontro do outro, porque sabe que é a condição para se completar. Precisamos do outro para completar-nos e para enfrentarmos a nossa precariedade (DIAS, 2004, p. 9).

Por fim, a dimensão da revivência:

É o modo como cada um de nós cria alternativas para enfrentar a finitude. Nós não queremos morrer, desejamos a eternidade. Através das obras da cultura nós podemos nos lançar na eternidade. A ampliação de nossas possibilidades no campo da 
revivência depende de um trabalho de construção de valores. O processo educativo é também um espaço e um tempo de construção de valores. Os nossos valores sustentam as nossas ações no campo da sobrevivência e no campo da convivência (DIAS, 2004, p.9).

No processo de formação de educadoras e educadores vivido durante a vigência do Projeto LETRAVIVA, como também em diferentes espaços onde atuamos, tanto na universidade, como nos programas de formação continuada em redes de ensino, ou ainda em grupos de Educação Popular, temos tido oportunidade de experimentar a criação partilhada de currículos vivos, construídos a serviço da manifestação da vida. Tais experiências são aqui reportadas com o desejo da partilha. Como oferta da palavra, pois "o solidário não quer solidão" (NASCIMENTO; BRANT, 1988).

Acreditamos que o currículo vivenciado e problematizado a partir das três dimensões da vida: sobrevivência, convivência e revivência, pode contribuir para a aproximação e reconhecimento dos saberes que educandos, educandas, educadores e educadoras são portadores. Pode favorecer a criação de novos conhecimentos, além de ampliar os campos de possibilidades para a vida se manifestar.

A EJA pode ser um tempo/espaço onde jovens e adultos, a partir da precariedade do viver, se unem para ensaiar novas formas de sobrevivência. A vinculação EJA/trabalho/sobrevivência indica que podemos criar oficinas, cursos, cooperativas de trabalho, valorizando o saber que os sujeitos possuem.

A dimensão da convivência serve de suporte para rompermos com o isolamento, o individualismo e o consumismo, impregnados na cultura da sociedade capitalista, seguidamente reafirmada na concepção tradicional de currículo. Podemos construir coletivamente possibilidades solidárias de enfrentamento e questionamento do individualismo incessantemente promovido pelas mídias e pelas avaliações que reafirmam a competitividade e a exclusão.

A partir da dimensão da convivência criamos encontros humanos solidários, construindo vínculos duradouros. Se desejamos mudar o nosso modo de ser e estar no mundo, podemos transformar a EJA em laboratório para novas experimentações, nos quais observamos, com cuidado e atenção, como estamos sendo (FREIRE, 2000b, p. 79) em cada encontro. Como nos relacionamos conosco mesmo, com o outro e com o mundo. Podemos constantemente nos perguntar se fomos capturadas ou não pela lógica do mercado, que nos faz crer que o sentido 


\section{e-Curriculum}

da vida está na quantidade de coisas consumidas ou na lista de conteúdos impostos pela sociedade mercantil.

Refletir sobre o currículo a partir da convivência é uma possibilidade que criamos de aprender a ouvir, muitas vezes, o que não é dito, somente manifesto com gestos ou silêncio. É acolher a dor do outro e respeitar ou transformar a nossa própria dor. É cuidar e dar sustentação a processos de reinvenção de si e do mundo, vivendo o pertencimento. Enfim, elaborar coletivamente possibilidades alternativas para os encontros humanos, que promovam o bem viver, pois sabemos que nos constituímos na relação com o outro, que nos completa e marca nossa existência de sentido.

Somos seres finitos, inconclusos, inacabados (FREIRE, 2003, p. 50) a nos debater em busca de possibilidades de ampliação da vida. Vivemos intensamente o desejo de esticar nossa existência. Esta precariedade nos impulsiona, nos põe em movimento de procura. Estamos em obra!

O que temos visto em nossas vivências e andanças é que um ambiente acolhedor pode ser terreno fértil para novas experimentações, no qual o potencial criador das pessoas encontra segurança para ser exposto. Educandos, educandas, educadores e educadoras podem inventar ambientes onde ensaiem se desprender das amarras impostas pela sociedade de controle. Como afirmamos, temos visto experiências nas quais a EJA se manifesta como um espaço de criação, de reinvenção de si e do mundo. Sabemos que não precisamos continuar a repetir o presente, pois, em muitas situações essa repetição tem provocado dor, sofrimento e sentimento de impotência.

Temos conosco o desejo de instigar o potencial imaginativo, inventivo, existente em cada educador, educadora, educando e educanda. Desejamos contribuir com a reinvenção da EJA. O diálogo sobre currículo aqui ofertado é um convite para repensarmos e recriarmos o modo como estamos nos relacionando com a produção do conhecimento.

Podemos, sim, nos perguntar o que ensinar?, mas esta pergunta terá sentido se nos perguntarmos coletivamente por que?; para quem?; a serviço de qual sociedade atuamos?; qual tipo de formação humana estamos gestando com os currículos praticados? De que maneira nosso trabalho tem afetado a vida das pessoas?

Cremos que uma outra educação é possível e que um outro mundo também é possívelii . Porém esta mudança não acontecerá por decreto. Precisará ser gestada em cada encontro 
humano desenvolvido durante as aulas, nos corredores das instituições, nos pátios, nas áreas de lazer, nas comunidades de convívio, nutrindo a curiosidade epistemológica encharcada nas águas do cotidiano. Aprender e criar conhecimentos nesse contexto passa a ter um novo sentido.

Considerando a dimensão da convivência, vínculos duradouros podem ser criados produzindo efeitos significativos na vida de sujeitos que, amparados nessa rede solidária, se lançam no movimento de experimentação. Nesse ambiente saberes antes considerados hierarquicamente inferiores são compartilhados, afirmando o potencial criativo das pessoas, em uma maneira singular de impregnar de vida o currículo.

Refletir e viver o currículo como prática dialógica potencializa a vida dos educandos e educandas, como também das educadoras e educadores da EJA, fazendo deste tempo/espaço uma experiência de “educação como prática da liberdade” (FREIRE, 2002). 


\section{$e$-Curriculum}

\section{REFERÊNCIAS}

ANTUNES, Arnaldo; TATIT, Paulo. O seu olhar. Intérprete: Arnaldo Antunes. In: ANTUNES, Arnaldo. Ninguém. Rio de Janeiro: Sony BMG, 1994. 1 CD. Faixa 9.

BARRETO, José Carlos. Um sonho que não serve ao sonhador. In: Construção coletiva: contribuições à educação de jovens e adultos. Brasília: UNESCO, MEC, RAAAB, 2005. p. 63- 68.

BRANDÃO, Carlos Rodrigues (Org.). A questão política da Educação Popular. 4. ed. São Paulo: Brasiliense, 1984.

Educação Popular. São Paulo: Brasiliense, 1984.

A pergunta a várias mãos: a experiência da pesquisa no trabalho do educador. São Paulo: Cortez, 2003.

CAMPOS, Ana Maria de. Diálogos com quem ousa educar, educando-se - a formação de educadores a partir de uma experiência de educação popular. 2009. Dissertação (Mestrado em Educação) - Faculdade de Educação, Pontifícia Universidade Católica de Campinas, Campinas, 2009. Disponível em:

$<$ http://www.bibliotecadigital.puccampinas.edu.br/tde busca/arquivo.php?codArquivo=511\&PHPSESSID=6b2b645d8f815d2c e153c4dfefb8a1c9>. Acesso em: 17 out. 2017.

CAMPOS, Ana Maria de; PACHANE, Graziela Giusti. Diálogos com quem ousa educar, educando-se: a formação de educadores a partir de uma experiência de Educação Popular. Currículo sem Fronteiras, v. 12, n. 03, p. 217-235, set/dez 2012. Disponível em: $<$ http://www.curriculosemfronteiras.org/vol12iss3articles/campos-pachane.pdf>. Acesso em: 17 out. 2017.

CAMPOS, Ana Maria de. Histórias contidas e nem sempre contadas na formação de jovens e adultos. 2014. Tese (Doutorado em Educação) - Faculdade de Educação, Universidade Estadual de Campinas, Campinas, 2014. Disponível em: <http://repositorio.unicamp.br/handle/REPOSIP/254097>. Acesso em: 17 out. 2017.

CARTA CAPITAL. Brasil está entre os dez países que concentram a maior parte do número de analfabetos. Carta Capital, 29 jan. Página Inicial / Educação, 2014. Disponível em: <http://www.cartacapital.com.br/educacao/taxa-mundial-de-analfabetismo-cai-1-em-11anos- mostra-relatorio-5540.html>. Acesso em: 17 out. 2017.

CERTEAU, Michel de. A invenção do cotidiano: artes de fazer. 15. ed. Petrópolis: Vozes, 2008.

COSTA, Marisa Vorraber (Org.). O currículo nos limiares do contemporâneo. 4. ed. Rio de Janeiro: DP\&A, 2005. 
DIAS, Romualdo. Projeto LETRAVIVA. Campinas: Secretaria Municipal de Educação, 2004.

Educação de Jovens e Adultos: novas perspectivas. Curitiba: Appris, 2015.

FREIRE, Paulo. Pedagogia do oprimido. 10. ed. Rio de Janeiro: Paz e Terra, 1981.

Educação: o sonho possível. In: BRANDÃO, Carlos Rodrigues (Org.). O educador: vida e morte. 9. ed. Rio de Janeiro: Graal, 1989, p. 89-101.

Extensão ou comunicação? Tradução Rosiska Darcy de Oliveira. 10. ed. Rio de Janeiro: Paz e Terra, 1992.

Política e educação. 4. ed. São Paulo: Cortez, 2000a.

$2000 \mathrm{~b}$.

Pedagogia da indignação: cartas pedagógicas e outros escritos. São Paulo: UNESP,

Educação como prática da liberdade. 26. ed. Rio de Janeiro: Paz e Terra, 2002.

Pedagogia da autonomia: saberes necessários à prática educativa. 27. ed. São Paulo: Paz e Terra, 2003.

FREIRE, Paulo; NOGUEIRA, Adriano. Que fazer: teoria e prática em Educação Popular. 8.ed. Petrópolis: Vozes, 2005.

GARCIA, Pedro Benjamim. Educação Popular: algumas reflexões em torno da questão do saber. In: BRANDÃO, Carlos Rodrigues (Org.). A questão política da Educação Popular. 4. ed. São Paulo: Brasiliense, 1984. p. 88-121.

GARCIA, Pedro. Uma experiência de formação de leitores, com camadas populares, através de rodas de leitura. In: RIBEIRO, Vera Masagão. (Org.) Educação de jovens e adultos: novos leitores, novas leituras. Campinas: Mercado de Letras: ALB; São Paulo: Ação Educativa, 2001. p. 81-87.

GERALDI, João Wanderley. A aula como acontecimento. São Carlos: Pedro \& João Editores, 2010.

GRANVILLE, Maria Antônia (Org.). Currículos, sistemas de avaliação e práticas educativas: da escola básica à universidade. Campinas: Papirus, 2011.

LARROSA, Jorge. Notas sobre a experiência e o saber de experiência. In: GERALDI, Corinta Maria Grisolia et al. (Orgs.). Escola viva: elementos para a construção de uma educação de qualidade social. Campinas: Mercado de Letras, 2004. p. 113-132. 


\section{$e$-Curriculum}

Programa de Pós-Graduação em Educação: Currículo

MOREIRA, Antônio Flávio. A crise da teoria curricular crítica. In: COSTA, Marisa Vorraber (Org.). O currículo nos limiares do contemporâneo. 4. ed. Rio de Janeiro: DP\&A, 2005. p. 11-36.

NASCIMENTO, Milton; BRANT, Fernando. Coração Civil. Intérprete: Milton Nascimento. In: NASCIMENTO, Milton. Caçador de Mim. Rio de Janeiro: Philips, 1981. 1 Disco Sonoro. Lado B, faixa 4.

NASCIMENTO, Milton; TISO, Wagner. Coração de estudante. In: NASCIMENTO, Milton. Milton Nascimento ao vivo. São Paulo: Barcley, 1983. 1 Disco Sonoro. Lado 1, faixa 1.

NASCIMENTO, Milton; BRANT, Fernando. Bola de meia, bola de gude. Intérprete: Milton Nascimento. In: NASCIMENTO, Milton. Miltons. Rio de Janeiro: CBS, 1988. 1 disco sonoro. Lado 2, faixa 4.

PEREIRA, Dulcinéia de Fátima Ferreira. Educação popular: uma experiência no cenário dos anos 90. 1999. Dissertação (Mestrado em Educação) - Faculdade de Educação, Universidade Estadual de Campinas, Campinas, 1999. Disponível em:

<http://repositorio.unicamp.br/jspui/handle/REPOSIP/253243>. Acesso em: 17 out. 2017.

PEREIRA, Dulcinéia de Fátima Ferreira. Revisitar Paulo Freire: uma possibilidade de reencantar a educação. 2006. Tese (Doutorado em Educação) - Faculdade de Educação, Universidade Estadual de Campinas, Campinas, 2006. Disponível em:

<http://repositorio.unicamp.br/jspui/handle/REPOSIP/251870>. Acesso em: 17 out. 2017.

PINTO, Álvaro Vieira. Sete lições sobre educação de adultos. 7. ed. São Paulo: Cortez: Autores Associados, 1991.

RESTREPO, Luiz Carlos. O direito à ternura. Petrópolis: Vozes, 2000.

ROLNIK, Suely. Pensamento, corpo e devir. Cadernos de Subjetividade: revista do Núcleo de Estudos e Pesquisas da Subjetividade do Programa de Pós-Graduação em Psicologia Clínica da PUC, São Paulo, v.1, n.2, p. 241- 251, set. /fev. 1993. Disponível em:

<http://www.pucsp.br/nucleodesubjetividade/Textos/SUELY/pensamentocorpodevir.pdf>.

Acesso em: 17 out. 2017.

SANTOS, Boaventura de Sousa. Para uma pedagogia do conflito. In: SILVA, Luis Heron da (Org.). Novos mapas culturais, novas perspectivas educacionais. Porto Alegre: Sulina, 1996.

SILVA, Tomás Tadeu. O que produz e o que reproduz em educação: ensaios de sociologia da educação. Porto Alegre: Artes Médicas, 1992.

Documentos de identidade: Uma introdução às teorias do currículo. Belo Horizonte: Autêntica, 2001. 
SOARES, Leôncio José Gomes; SILVA, Fernanda Rodrigues; SOARES, Rafaela Carla e Silva. Educação de jovens e adultos e propostas curriculares: (re)conhecer especificidades dos sujeitos. In: $37^{\mathrm{a}}$ Reunião Nacional da ANPEd, 2015, Florianópolis.

Anais eletrônicos da 37 ${ }^{\mathbf{a}}$ Reunião Nacional da ANPEd, Florianópolis, 2015. Disponível em: 〈http://37reuniao.anped.org.br/wp-content/uploads/2015/02/Trabalho-GT18-4639.pdf>.

Acesso em: 17 out. 2017.

UNESCO - ORGANIZAÇÃO DAS NAÇÕES UNIDAS PARA A EDUCAÇÃO, A CIÊNCIA E A CULTURA. Relatório de Monitoramento Global de Educação para Todos. EFA Global Monitoring Report. Paris, n. 11, 2014. 56 p.

\footnotetext{
i Esta afirmação de Paulo Freire foi apresentada por Carlos Rodrigues Brandão no livro Educação Popular, de 1984, e orientou a formulação de uma reflexão em torno do tema: Dizer a Palavra, que abre e encerra o livro.

ii Um outro mundo é possível: "Tema do Fórum Social Mundial. O FSM é um espaço de debate democrático de ideias, aprofundamento da reflexão, formulação de propostas, troca de experiências e articulação de movimentos sociais, redes, ONGs e outras organizações da sociedade civil que se opõem ao neoliberalismo e ao domínio do mundo pelo capital e por qualquer forma de imperialismo" (CAMPOS, 2009, p.50).
} 